\title{
Impact of single use polyethylene shopping bags on environmental pollution, a comprehensive review
}

\author{
Ayesha Hussain ${ }^{1}$, Zafar Javed ${ }^{2 *}$, Farzana Kishwa ${ }^{3}$, Muhammad Kashif \\ Bangash $^{4}$, Hafiz Muhammad Zeeshan Raza ${ }^{5}$ and Mehrin Farooq ${ }^{6}$ \\ 1. Department of Home Economics, Government College Women University Faisalabad. Pakistan \\ 2. National Textile University Faisalabad-Pakistan \\ 3. Government College Women, Lahore-Pakistan \\ 4. Department of Textile Engineering and Technology, University of the Punjab, Lahore-Pakistan \\ 5. Biosciences Department, COMSATS University Islamabad, Sahiwal Campus, Pakistan \\ 6. The Islamia University of Bahawalpur. Pakistan \\ *Corresponding author's email: zafar@ntu.edu.pk \\ Citation \\ Ayesha Hussain, Zafar Javed, Farzana Kishwa, Muhammad Kashif Bangash, Hafiz Muhammad Zeeshan Raza \\ and Mehrin Farooq. Impact of single use polyethylene shopping bags on environmental pollution, a \\ comprehensive review. Pure and Applied Biology. Vol. 9, Issue 3, pp1962-1975. \\ http://dx.doi.org/10.19045/bspab.2020.90209
}

\begin{tabular}{llll}
\hline \hline Received: 27/02/2020 & Revised: 18/05/2020 & Accepted: 22/05/2020 & Online First: 02/06/2020 \\
\hline
\end{tabular}

\section{Abstract}

Thousands of plastic factories are manufacturing tons of plastic products and plastic goods. Plastic-made products and bags are widely used worldwide due to the advantages of convenience, availability, and cheapness. Because of the non-biodegradable nature, plastic causes many negative and hazardous impacts on the ecosystem and environment. Recently many countries, including Pakistan, Yemen, Bangladesh, South Africa, India, Nigeria, and Kenya, have banned the plastic bags because of the pressing concerns over the negative and hazardous impact on the water, land, and marine ecosystem and natural environment. The primary cause of environmental pollution is the disposal of plastic wastes. The trend of dumping plastic garbage into the marine ecosystem, jeopardize the survival of enormous species because of infections with plastic scraps. Many species have already announced to be endangered due to anthropogenic activities. Marine animals are affected by the ingestion and entanglement of plastic litter. Tackling plastic waste is one of the major issues of environmental pollution. Many steps are necessary to be taken by the governments to regulate the plastic businesses and to bring innovations in the waste management. Creating public awareness regarding the healthy environment, managing wastes, alternative disposal methods, establishing the incineration mechanisms, and drop-off-areas facilities for plastic recycling also recommended to ensure a healthy environment. This review paper emphasizes the hazardous of single-use polyethylene shopping bags on the environment and the emerging trends to tackle the management of plastic wastes. It also offer help for policymakers to consider regulatingthe manufacture and use of plastic bags.

Keywords: Anthropogenic activities; Environmental pollution; Non-biodegradable waste; Polyethylene Plastic products; Plastic bags waste; Waste management

\section{Introduction}

Since 1970 the plastic bags utilization has been observed [1] and its use gained rapid popularity in retailers, customers, and consumers. Across the world, plastic bags are available in many varieties and large 
amounts. About 500 billion plastic bags are being used annually around the globe [2]. The utilization of plastic bags is due to the significant attributes of convenience and cheapness. After a single-use, the majority of the plastic bags are discarded and thrown as litter or waste. The estimated persistent time of plastic bags in the environment is up to 1000 years. It requires natural degradation and disposal of plastic that is a great challenge without being degraded by the light of the sun or microbes [3]. The accretion of plastic bags and their wastes causes many types of environmental pollution, which can be manifested in a variety of ways. The primary concern is the deterioration of the natural environment and its beauty [4]. Many other common issues coupled with plastic wastes are deaths of wild as well as domestic animals, marine species, etc. In order to safeguard the different species which are near to the point of extinction, necessary proactive measures must be taken $[5,6]$. Sewerage systems blockages also a common problem aroused due to plastic bags in cities. The instruments like taxes and levies must be implemented to restrict the production and use of plastic bags $[7,8]$. To reduce the plastic bag usage and problems due to respective wastes in the environment, the voluntary initiatives along with taxes and levies have also been implemented in many countries. The utilization of plastic bags has been dramatically increased due to light in weight and wind can take them everywhere. The plastic bags are also very cheap to be recycled or reused. The spread of plastic bags in the environment also brought about pollution and environmental damage. Due to plastic bags proliferation scene of environment replaced derision. Various reports [9] revealed that plastic bags are a source of causing severe health damages in humans, animals and cause environmental pollutions. The major reasons behind this detrition of environment are poor management of waste and lack of awareness regarding negative and hazardous impacts of plastic bags on the environment [10]. The basic aim of this review was to evaluate major effects of single use polythene bags on the environment and to suggest the strategies and methods employed to avoid hazardous effects in near future.

\section{Consumption and future predictive production of polythene bags}

The manufacturing and utilization of polythene bags and plastic items have enormously increased as compared to other materials, because of the rapid shift of durable plastic production of single-use plastics. The manufacture of plastic is chiefly contingent on hydrocarbons fossil, which is referred as the non-renewable resources [11]. If the production of plastic continues to grow at the same rate, it is estimated that the plastic industry may account for $20 \%$ of total oil of the world until 2050 [12]. In North-East Asia, including China, Taiwan, Korea Hong, Kong and Japan, the single-use plastics manufacturing consumes more than onefourth of the entire world's resins [13]. This manufacturing is followed by Europe, Middle East and North America. The observation of the plastic wastes can help to estimate the total global production and consumption of plastic, as shown in (Fig. 1). Plastic packing is referred as the singleuse, particularly the application in plastic business and customer, and most of the plastic is also redundant the same year in which it is manufactured. Out of overall global wastes, $47 \%$ observed to be a waste of plastic packing, in 2015, and most importantly, Asia accounts for half of the total plastic waste. However, worldwide the biggest generator of plastic wastes is China [14]. 


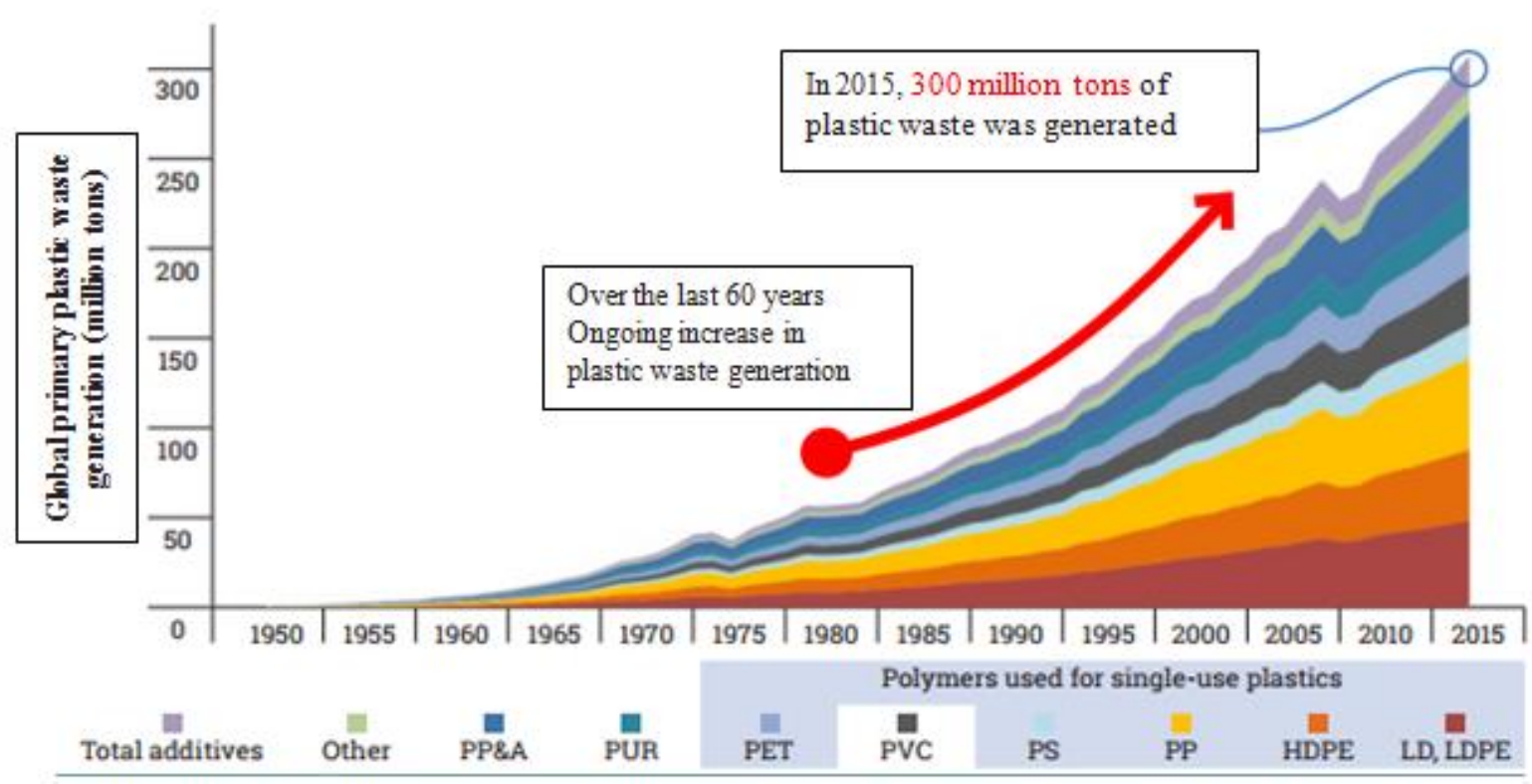

Figure 1. Global plastics waste generation 1950 - 2015[15]

The recent estimates suggested that $79 \%$ of total plastic waste is formed till date resides in dumps, landfills, and environment. Consequently, due to less robustness in data, precautions and actions against usage of plastic bags, it is not possible yet to demonstrate the breakdown similar in all the regions. Likewise in December 2017 the European parliament, council and commission conclude a preliminary agreement to set a packaging recycling target of $65 \%$, till 2025, further will be increased to $70 \%$ till the year 2030 . The plastic packaging recycling specific goal is observed to be $50 \%$ till 2025 , and $55 \%$ till the end of 2030.Based on per-capita the United States of America (USA) is the largest producer of plastic packing waste, subsequently, Japan and Europe followed the list (Fig. 2).

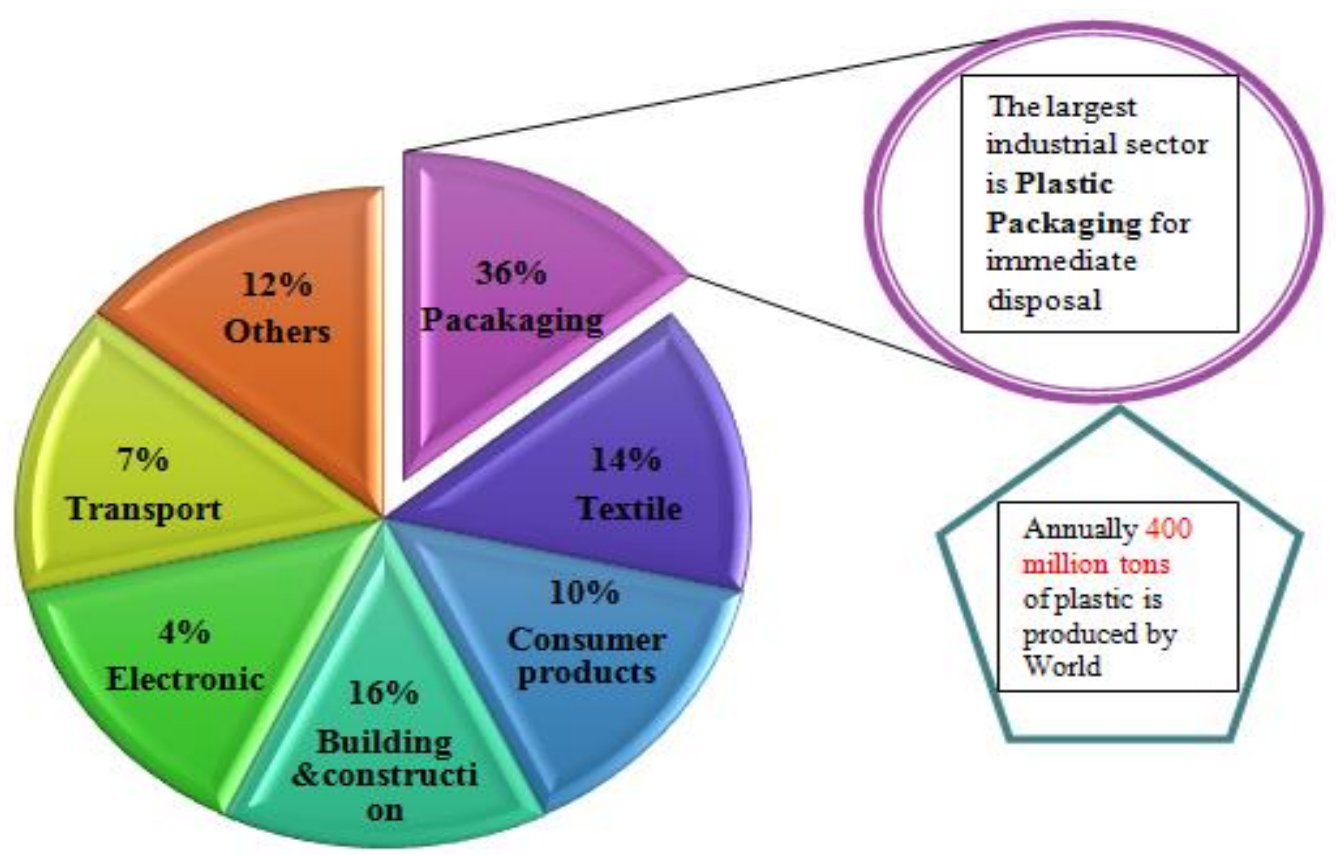

Figure 2. Global plastic production (2015) 
If the production, consumption and management practices of plastic utilization do not improve rapidly, it is estimated that approximately 12 billion tons plastic litter and waste will become the part of natural landfills and environment 2050 [15]. Processes of energy recovery are the most preferable instead of improper management of waste and landfill. Nevertheless, to set up the infrastructures of energy recovery, it would require mega investments and indirectly discourages the policies boosted for the reduction of generating plastic waste. The management of waste hierarchy and prevention of pollution by plastic waste must always be the utmost priority.(Fig. 3) demonstrates the countries who are involved in producing vast and mismanaged wastes of plastic and plastic products [16].

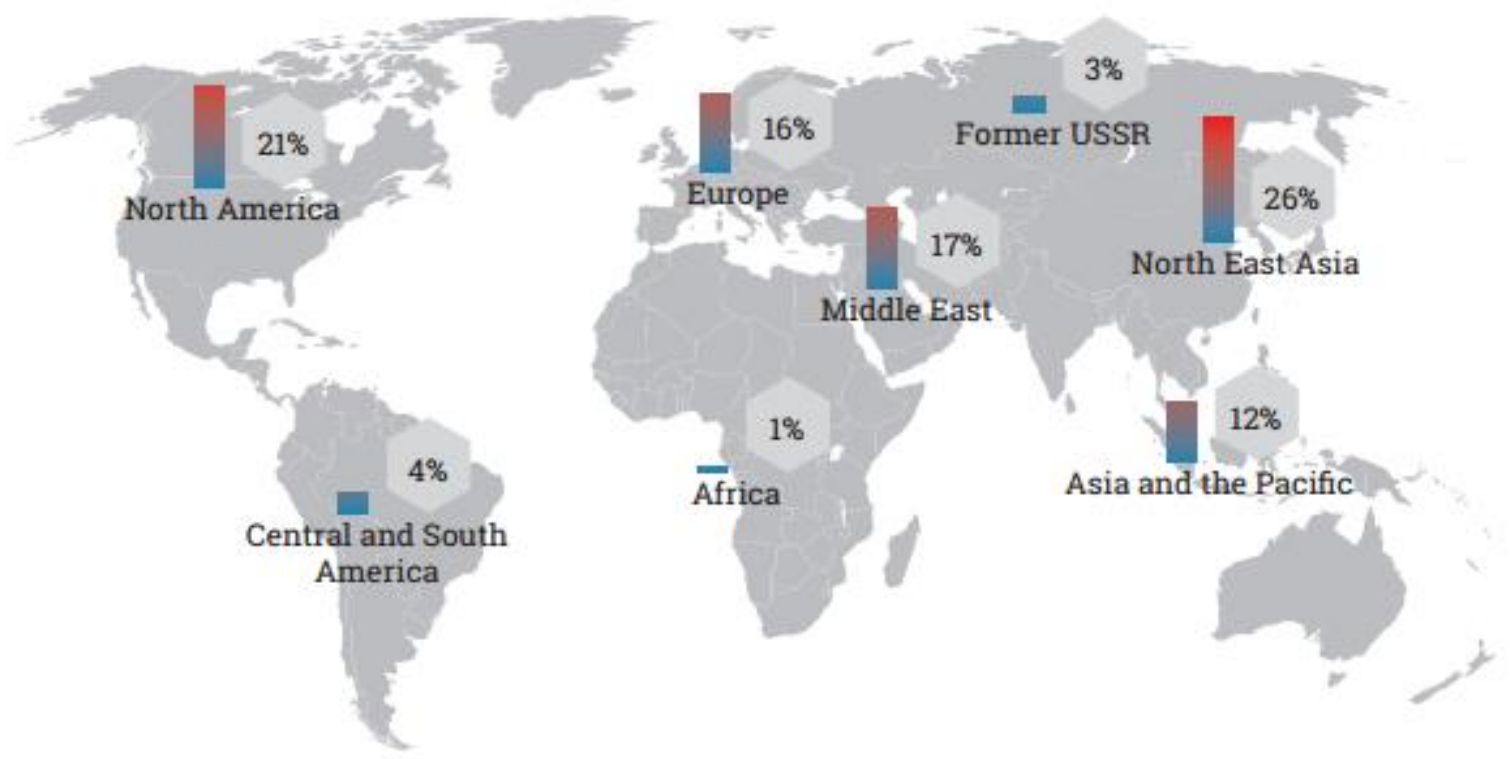

Figure 3.Polythene bags regional distribution and manufacture [17]

\section{Single-use plastic shopping bags}

Plastic is a resistant and trivial substance that can be transformed and molded indifferent shapes and has an extensive range of utilization and applications as illustrated in (Table1). The plastics do not corrode or rust like various metals. Most of the plastics types are non-biodegradable but has the ability to photo-degrade. It is slowly converted into small pieces or fragments which are referred as micro-plastics [18]. The fragmentation or break down of large items of plastic items into smaller microplastics is commonly observed on beaches due to effects of high radiations of ultraviolet (U.V.) and abrasion caused by water waves, but process of degradation is very slow in sea and oceans because of low temperatures and less exposure of high
U.V. irradiations [19]. The Single-use plastics or plastic bags are usually known as the disposable material which is frequently used in packaging, including products which are only used once and then discarded, wasted or reused after Recycling. It includes containers, grocery bags, straws, cups, food packaging, cutlery and bottles. The most common usage of Single-use plastic bags is to carry items or goods at sale points to the customers. The shopping bags are usually made of a plastic type known as polythene or polyethylene. Polyethylene is a synthetic resin which is flexible, light and robust. It is manufactured by carrying out the polymerizing process of ethylene [20]. The polymers used in production and manufacturing of Single use plastic bags is demonstrated in (Fig. 4). 


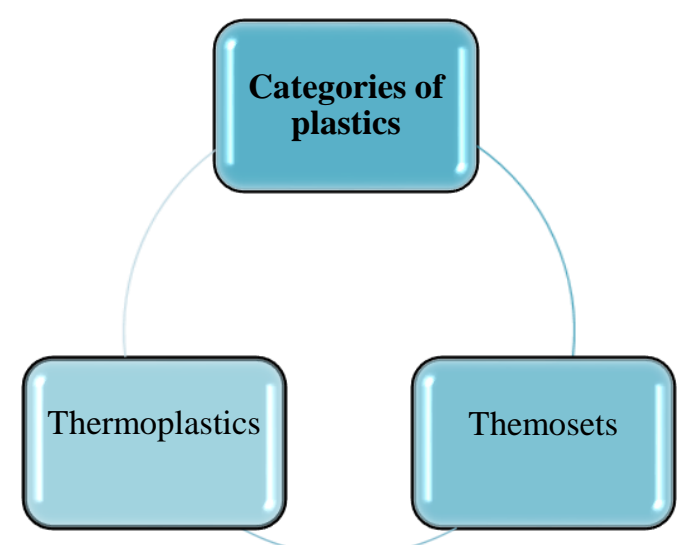

Figure 4. Categories of plastics

Table 1. Examples and single-use plastic and their applications

\begin{tabular}{|c|c|c|}
\hline Plastics types & Examples & Applications \\
\hline Thermoplastics & $\begin{array}{c}\text { Polyethylene Terephtalate (PET), } \\
\text { low-density polyethylene (LDPE) } \\
\text { and high-density polyethylene } \\
\text { (HDPE), Expanded polystyrene } \\
\text { (EPS), Polyvinyl chloride } \\
\text { Polycarbonate (PVC) }\end{array}$ & $\begin{array}{c}\text { Thermoplastics are molded form of plastic } \\
\text { which can be changed into different forms } \\
\text { upon heating and slow cooling it is also } \\
\text { referred as the reversible type of plastic. It } \\
\text { has the capability of reshaping, reheating, } \\
\text { repeatedly }\end{array}$ \\
\hline $\begin{array}{c}\text { Polyurethane (PUR), Silicone, } \\
\text { Phenolic, Epoxy, Acrylic, Urea- } \\
\text { formaldehyde (U.F.) resins, Vinyl } \\
\text { ester }\end{array}$ & $\begin{array}{c}\text { Thermosets undergo a permanent } \\
\text { chemical change upon heating, resulting } \\
\text { in 3D network. It cannot be reform }\end{array}$ \\
\hline
\end{tabular}

\section{Emerging trends of polythene management}

To encounter such plastic pollution issues, global commitments emphasize a broadspectrum sentiment against single-use. Various actions can be taken by private, public sector and the entities of governments which are aimed at reduction of production, manufacture and utilization of Styrofoam and plastic bags [21]. Improvements in the management of waste, environment-friendly alternative promotion, social awareness, voluntary agreements and minimization strategies, Recycling [22], permanent bans on plastics and polystyrene, utilization of solar energy, trash emptying wireless monitoring [23] and increased composting in houses, cafeterias and restaurants

\section{Improvements in the systems of waste} management

Permanent bans on polythene bags and items made of Styrofoam can efficiently resolve many hazardous effects. Nevertheless, innovative and effective methods for waste management, in conjunction with circular thinking, can facilitate to achieve a long-term solution to encounter the issues of plastics bags and their impact on the environment[24]. Schematic waste management system to minimize dumping and landfilling[25] is shown in (Fig. 5) and the circular economy [19] and its stakeholders in (Fig.6). 

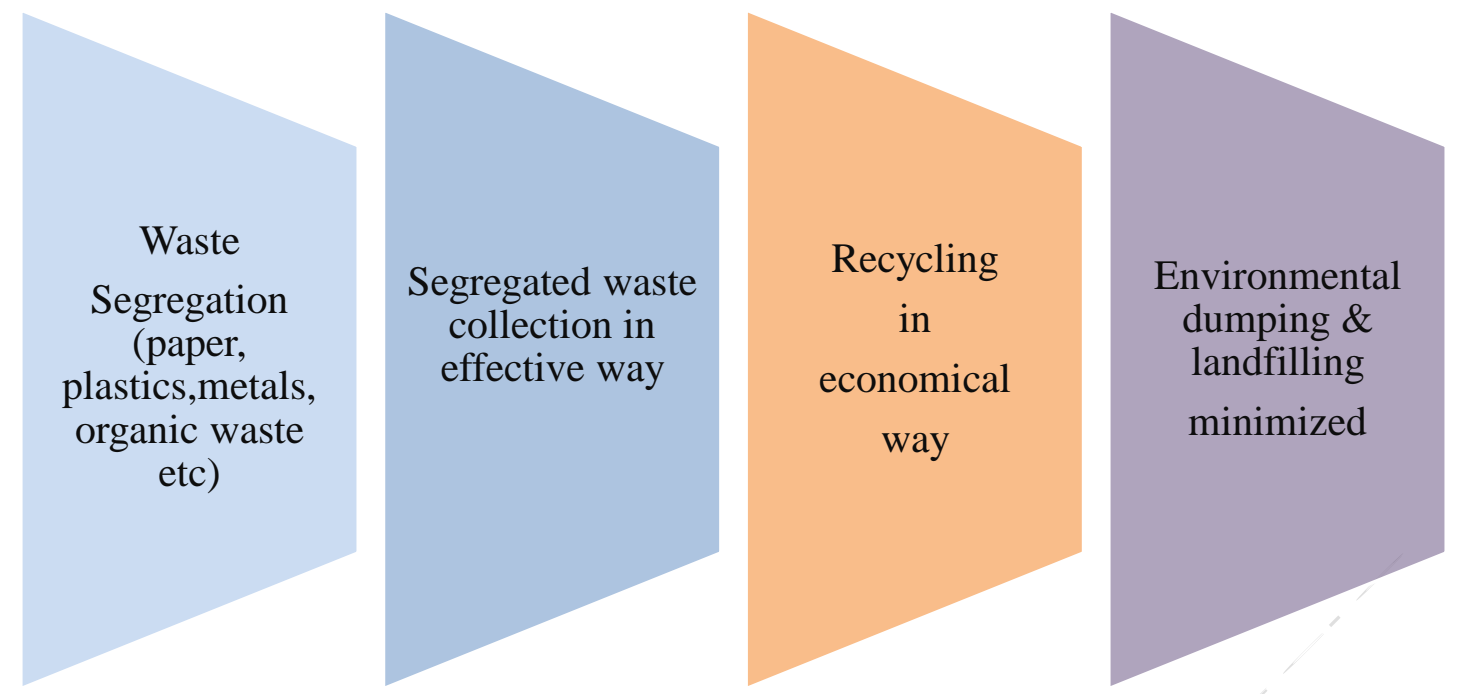

Figure 5. Schematic waste management system to minimize dumping and landfilling

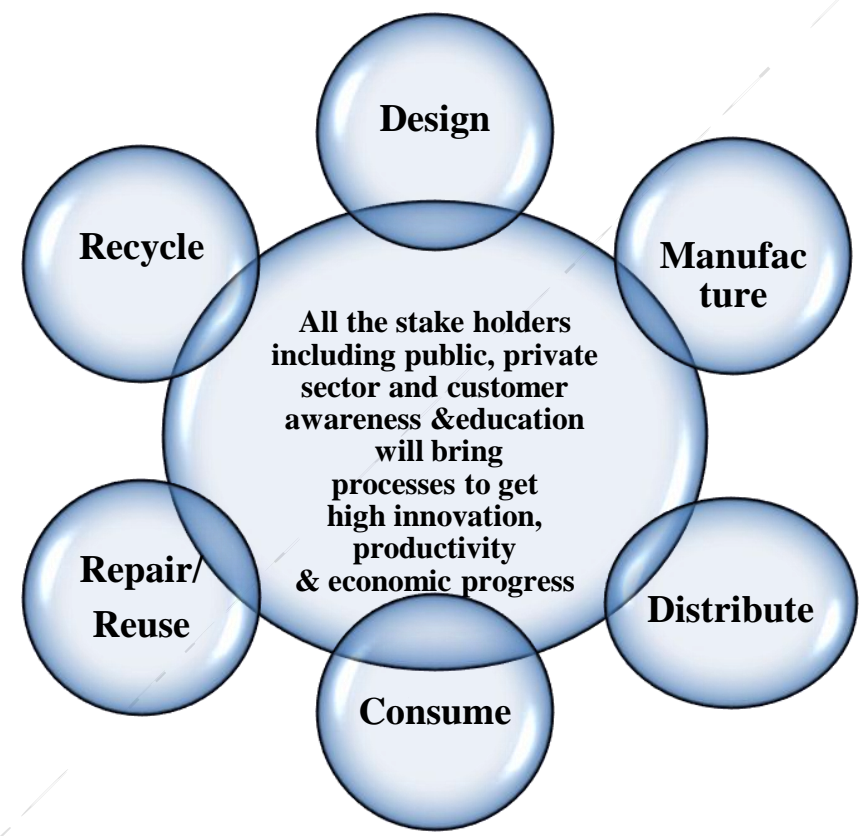

Figure 6. Circular economy[19]

Many research studies showed the attitude, behavior, attitude and effects of public policies towards the consumption of plastic bags in individual countries, like England [26], Botswana [27], Ireland [28], USA [29], Portugal [30] and in cities, like Toronto [31], Buenos Aires [32] federal states [33]. Some studies consider a global perspective on the use of plastic bag initiatives [34-36]. Many public policies aimed at the restriction of plastic bag use has also significantly increased since 2000 . In 2003 , there were only 20 policies which increased to 160 in 2018 [35]. Bans and levies have been put in various countries. eleven states of the U.S. have enacted laws to confine local governments from adaptability to plastic bags [29]. Many countries have also introduced the regulations and policies on the usage of plastic bags and Styrofoam products they includes, France, Ireland, Hungary, USA, China, Australia, Benin, Botswana, Burkina Faso, Egypt, Africa, Ethiopia, Gambia, Kenya, Morocco, South Africa, Tanzania, Uganda, Tanzania, Bangladesh, 
Bhutan, China, India, Pakistan and many more [37].

\section{Impacts of polythene bags on environment}

Many research reported that the degradation of Styrofoam and polythene containers and bags need hundreds or thousands years. There are many hazardous effects of plastic bags on the environment [38] which includes the pollution and contaminating of water, and land soil thus renders the cause of significant tangling, ingestion and choking hazards to the aquatic [39], domestic and wildlife [40] because of balloon shape and negligible weight they can easily blow up and travel by air or ends up in distant land, ocean and beaches. The shopping bags impact on the environment can be observed in the form of photochemical oxidation, fossil fuels, eutrophication, global warming, water and land use.

\section{Impacts of polythene bags on health}

Plastic materials contain heavy chemicals like benzene and styrene, which are toxic and are referred as carcinogenic. It can cause many harmful effects on the health of animals and humans mainly affects respiratory, nervous, digestive, reproductive(Fig.7)and other vital systems, and also cause damage to liver and kidneys [41]. The toxins found in polystyrene and Styrofoam can be transferred through containers of drinks and food. The risk is observed to be accentuated by reheating of that the food in the container [42]. The domestic waste containing plastic items is seen to be frequently burnt. Irresponsible burning of plastic increases the emission of toxic fumes and gases containing dioxins and furans. In many countries, due to inadequate management and regulations of waste, litter and plastic bag intensify pandemics. The blockage of sewage provides high grounds of breeding pests and insects like mosquitoes, and thus, plastic bags can also elevate the risk of vector-borne diseases transmission, including malaria and dengue [34].

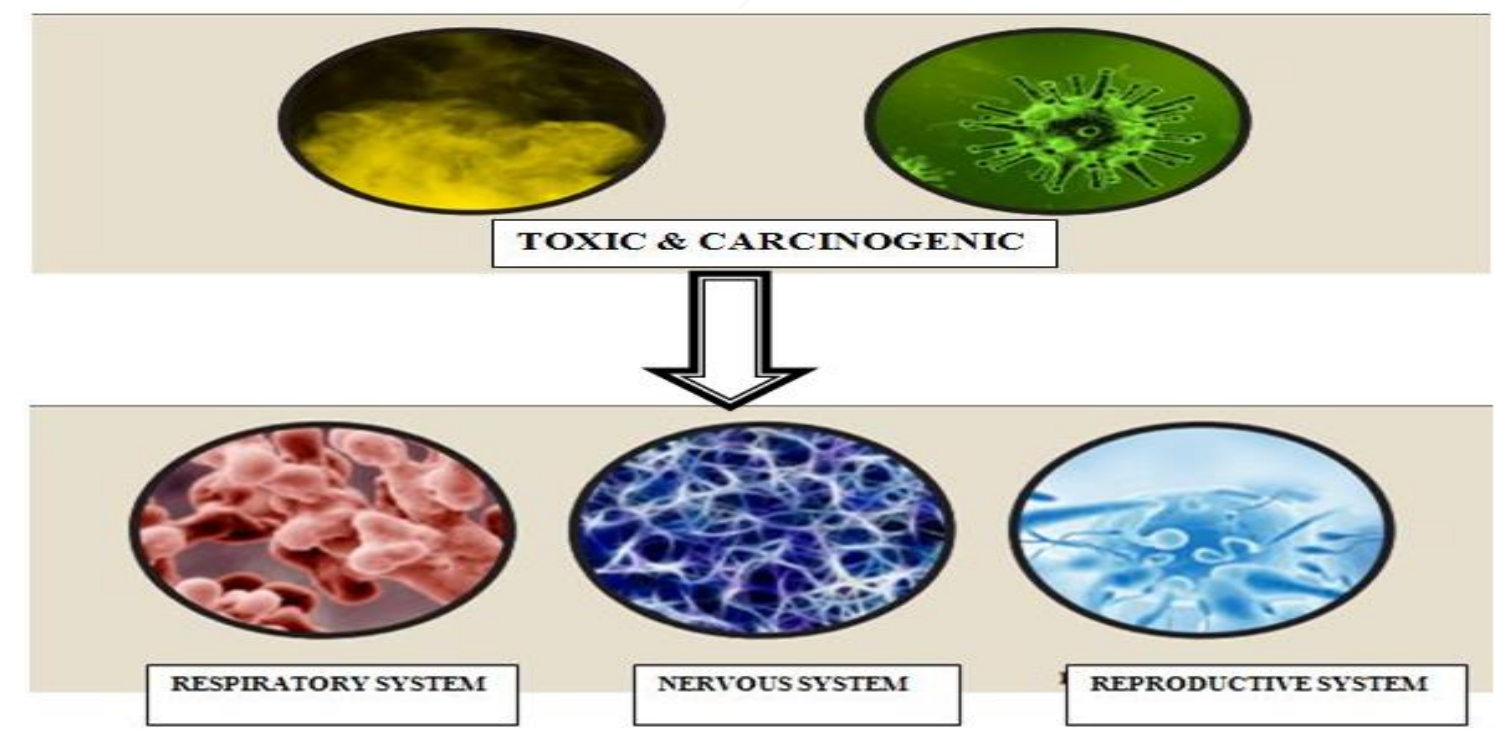

Figure7. Impacts of polythene bags on health

\section{Impacts of polythene bags on animals}

The high environmental level of plastic items produces momentous hazards to ecosystems of oceans and land, predominantly plastic shopping bags, have been observed to be the cause of blocking airways passages during breathing and blockage of digestive systems and stomachs of thousands of various animal species. In the marine ecosystem, the plastic bags in water seems like a jellyfish this cause the ingestion of plastic bags by many dolphins and turtles which mistakenly take it as food [43]. It is evident that various harmful 
chemicals and toxic materials are dissolved or added during manufacturing of the plastic which is ingested by many animals and transfer it into their blood, and different vital tissues eventually become the part of the food chain [44]. The breakdown of plastic bags converts it into small fragments called micro-plastic particles. The micro- plastic because of their size and the complex composition becomes hard even to detect or remove from the marine ecosystem and oceans [45]. Hence the primary strategy for effective mitigation is to minimize the input of plastic in the water (Fig.8).

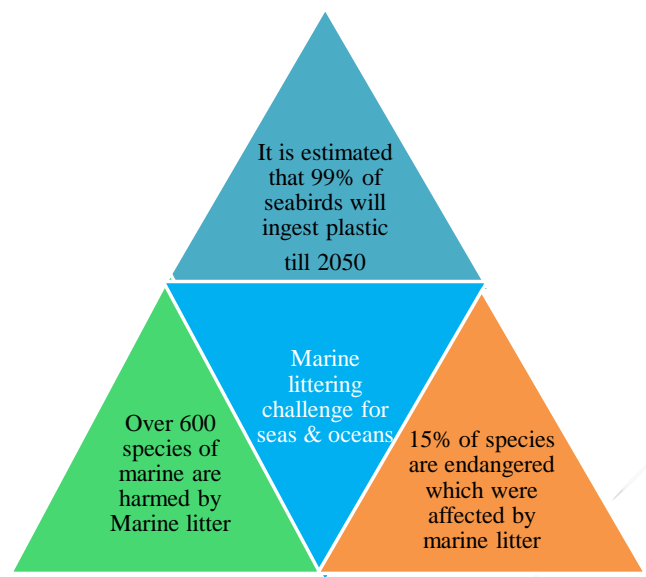

\section{Figure8. Impacts of polythene bags marine ecosystem}

Plastic bags can cause choking of natural waterways and may aggravate natural floods and disasters. In Bangladesh, during 1988, the failure of drainage system occurred due to clogging by plastic bag and litter resulted in devastating flooding, and many deaths [46]. According to the reported survey of 2015,16 third world countries with poor waste management are in the list of top 20 countries responsible for polluting marine ecosystem by plastic littering [16].

\section{Impacts of polythene bags on economy}

The major economic issue faced by plastic bags and plastic litters is developing countries and small islands, which majorly depend on tourism as a source of gross domestic product (GDP). Single-use plastic and plastic items also contribute to visual pollution. The economic impact on shipping, fishing, and tourism due to marine plastics is estimated to be approximately 1.3 billion dollars, according to Asia Pacific Economic Cooperation(APEC) alone in this region [47]. Styrofoam and some other type of plastics cannot be recycled unless provided with specialized plants. Due to the porosity nature of foamed plastic products, the clean-up of such items contaminate the drinks and food, which will increase the overall recycling cost. The cost estimated for cleaning beaches and shores is approximately 630 million Euros annually in Europe [48]. Research also revealed that the imparted damage on the economy due to plastics on the marine ecosystem is almost 13 billion dollars [49] (Fig.9).

\section{Alternatives to polythene bags}

Many countries have been replacing plastic shopping bags with biodegradable bags to reduce the utilization of single-use plastic bags [50]. The biodegradable items made of plastic include single-use plastic containers and bags detrition prolongs exposure to high temperatures approximately $50^{\circ} \mathrm{C}$. The plastics made of renewable natural resources like cassava roots corn, sugarcane, and starch [51] or by the process of fermentation of lipids and sugar by bacteria do not degrade automatically in the ecosystem or environment. 


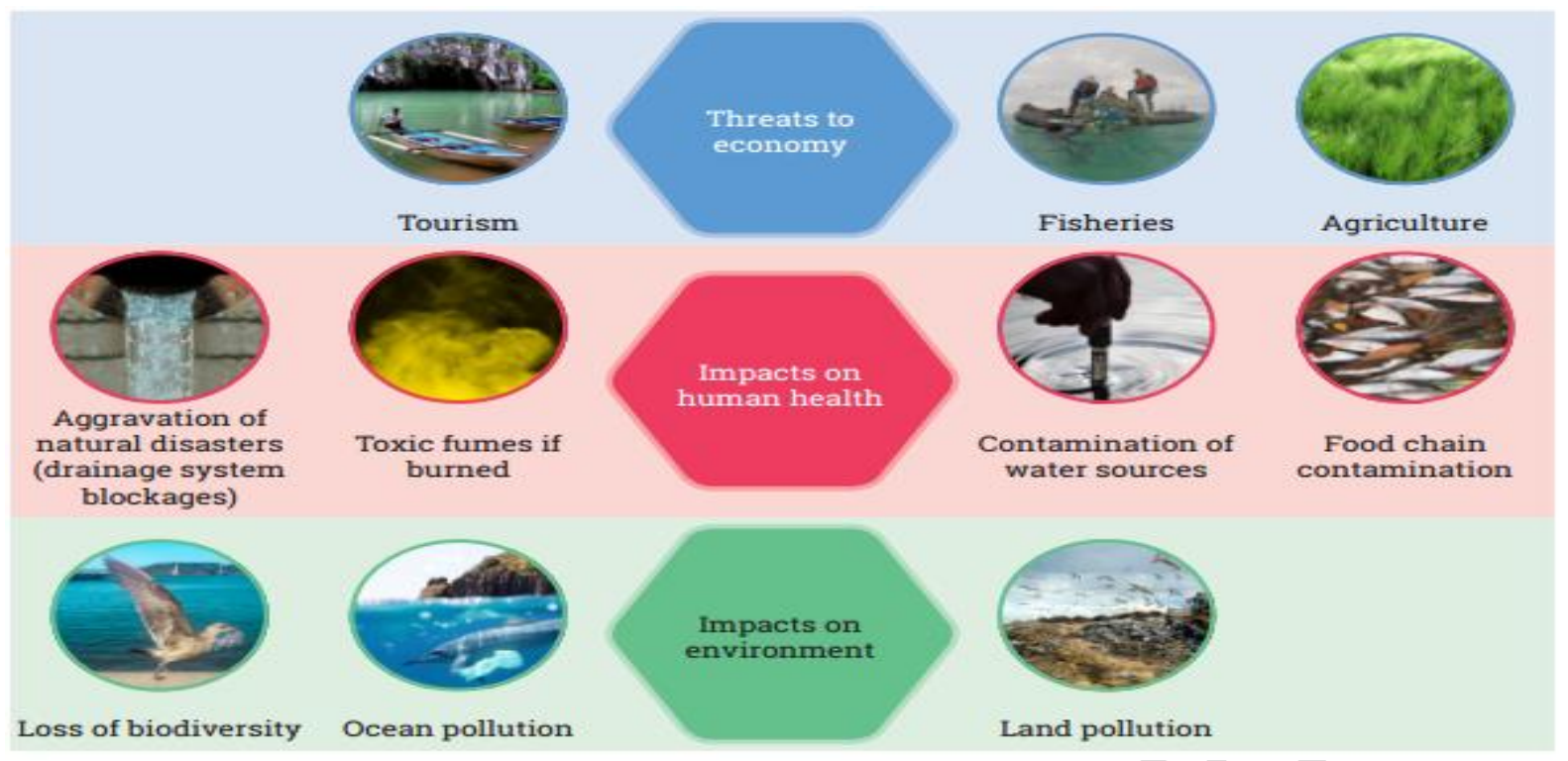

Figure 9. Impacts of single-use plastics and its examples

\section{Biodegradable plastics}

Biodegradable plastics include fossil-based and bio-based polymers on the basis of microbial assimilation and biodegradability degree. The process involved in plastic biodegradation involves hydrolysis, which may be enzymatic or non-enzymatic [52]. The major factors which play a key role in the efficiency of biodegradation are the type of microorganism, the pretreatment nature, Characteristics of a polymer. Moreover, crystallinity, molecular weight, mobility, functional groups, chemical components, tactility, and the nature of additives in plastics are also important aspects to consider in the degradation [53]. The degradation process occurs due to microbes which secrete enzymes involved in disintegration polymer and their complexes, convert into small fragments called monomers. These small fragments are used as energy sources of bacteria [54]. Both aerobic, as well as anaerobic reactions are involved in biodegradation [55].

Biodegradable plastics are classified as follows:

\section{Bio-based biodegradable plastics}

These are the plastics which are derived from renewable resources [56]. The examples of bio-based biodegradable plastics are starch, cellulose, and polymers based on starch. These are the polymers which are directly consumed by the microbes, by enzymes. The most commonly used biopolymer is Starch because of the advantages of abundance, availability, cheapness, as well as the ability of biodegradability in the environment [57].

The polymers of the starch and starch-based are classified as:

a. Starch-filled polymer

b. Starch-based polymer

These are the polymers that are readily degraded by different microbes like algae, fungi and bacteria [58]. The microorganisms like Comamonas species, Variovoraxparadoxus, Acidovoraxfaecilis, $P$. lemoigneiandAspergillus fumigates are observed to degrade all the bio-based plastics under anaerobic as well as aerobic processes [59]. Polyactic acid (PLA) and Polyhydroxyalkanoates (PHA) are conventional biodegradable polymers [60].

\section{Polyhydroxyalkanoates (PHA)}

It is biodegradable and belongs to the biobased polyester, which is produced by the lipids and sugar fermentation by bacteria [61]. It is readily degraded by Nocardiopsis, Bacillus, Cupriavidus, and Burkholderia, Micromycetes and Mycobacterium [62]. 
Polylactic acid (PLA)

It is also bio-based biodegradable plastic, which is derived from tapioca roots, corn starch, or sugarcane[63]. The species $B$. licheniformis and Amycolatopsis sp.[64] and Cryptococcus sp. are involved in its degradation biodegradation [65].

Fossil-based biodegradable plastics

Fossil-based biodegradable plastics have been used mainly in the packaging industry. In pharmaceutical products packaging, packaging of food items, makeup items, and the chemicals. Different microbes are involved in their degradation, but the process is too slow [66].

\section{Polyethylene succinate (PES)}

It is the type of thermoplastic polyesters synthesized by copolymerization of succinic anhydride and ethylene oxide. It is degraded by Pseudomonas species AKS2 a mesophilic bacterial strain [67]. It is degraded by microbial enzymes like esterases and lipases [68]. Aspergillus sp. has also been reported to degrade polycaprolactone (PCL) [69].

\section{Biodegradable polymer blends}

Making a blend of various polymers is a cheaper, faster, easier, and cost-effective method in comparison to the copolymerization method. These are wholly biodegraded by microbial enzymes. [70].

\section{Starch/polyester blends}

The blends of Starch and polyester are degradable because of their composition. The polyesters thermoplastics are versatile and can be used in genetic engineering. The microbial enzyme secreted by of $R$. delemar and $R$. arrhizus are involved in the hydrolysis of these blends [71].

Starch/ polyvinyl alcohol (PVA) blends Polyvinyl alcohol (PVA) being used in blends is fossil-based, aqueous soluble, and biodegradable. Various microorganisms have been reported to be involved in the enzymatic hydrolysis of starch/PVA blends [72].

\section{Management Strategies and Recommendations to reduce the use of Polythene Bags}

The management strategies which can be adopted for effective management of plastic waste are as follows:

\section{Improvements in the waste management system}

The permanent bans on single-use plastic and polythene bags and items made of Styrofoam can efficiently resolve many hazardous effects due to the overuse of plastic. Nevertheless, innovative and effective systems for waste management, in conjunction with circular thinking, can facilitate to achieve long-term solutions and impacts to encounter the issues regarding plastics bags and their effects on the environment.

\section{Environmental friendly substitute promotion}

The introduction of supporting projects, economic incentives that can assist in Recycling and scaling-up process of recycling the single-use plastic bags and items, and motivating the establishments of micro industries in private and governments sector can ensure the environmentally friendly substitute the plastics of single use [73].

\section{Social education and awareness}

Social education and awareness are the essential elements towards the change in perception and behavior of the consumers towards the usage of plastic bags. A steady, effective and the transformational progression is critical to achieving targeted goals. The change in attitude and cultural behavior regarding issues of pollution of the environment are not achievable only by brief campaigns of awareness [74]. It can be achieved by embedding the messages in regular practices and curriculums of schools from the very beginning. Strategies of Public awareness should not focus only the resources recycling or/and reuse, but also encourage the minimization and liable utilization of plastics and generation of waste. 


\section{Effective policies implementation:}

If the governments, public, private sector, and industries support collectively the promotion and development of effective policies against polythene and plastic bags and utilization of alternatives of plastics, the phase-out of single-use plastics bags can effectively and progressively achieve.

\section{Public pressure}

For the decision making of policies, the pressure exerted by the public can also trigger the response. The "Bye Bye Plastic Bags" social campaign was initiated in Bali, which leads the youth mobilization to do not use plastic bags. It lasted for four years until the ban of plastic bags on the island [75]. In New Zealand, the students of high school launched a petition to impose levy of0.10dollars on the markets using plastic bags 17,000 people signed after the launch of petition. This leads to recommendations to impose on plastic bag usage nationwide by the government [76]. Therefore the pressure by the public is also renowned as the precipitating choices of the private sector.

\section{Voluntary agreements}

It is also one of the reduction strategies which involve the Voluntary agreements among retailers, manufacturers, and the government to use plastic alternatives and prohibition on plastic bags. Private and public collaboration is a useful instrument in tackling this issue[35]. By building awareness in manufacturers and retailers can indeed change the behavior towards the usage of plastic bags. The main stakeholders who can effectively contribute towards the achievement of a healthy and clean environment are:

Entities of the local and national government, Authorities of waste management, Environmental Nongovernmental organizations (NGO's), Manufacturers of single-use plastics, Industry and trade associations, Retailers, Society groups, and citizens. Additionally, the awareness of the public regarding the importance of environment, controlling waste mechanisms, generation of plastics, alternative ways of disposal, the establishment of mechanisms of incineration and landfills, facilities of recycling plastic are also the significant recommendations.

\section{Conclusion}

There must be strict policies and regulations for restricting the use of polythene bags to a definite quantity. Awareness encampments should be planned in each corner of the metropolitan, particularly in slum zones to attentive people on confining the use of polythene bags and to only using biodegradable polythene bags. The maximum microbes that can decompose the polythene must be screened to distinguish the exact degradation mechanism.

\section{Authors' contributions}

Conceived and designed the experiments: A Hussain, Performed the experiments: $\mathrm{Z}$ Javed, Analysed the data: F Kishwa \& HMZ Raza, Contributed materials/ analysis/ tools: MK Bangash, Wrote the paper: A Hussain \& M Farooq.

\section{References}

1. Williamson L (2003). It's Not My Bag, Baby! On Earth 25(2): 32-34.

2. Spokas K (2008) Plastics-still young, but having a mature impact. J Waste Manage 28(3): 473-474.

3. Stevens ES (2002). Green plastics: an introduction to the new science of biodegradable plastics (Princeton University Press).

4. Adane L \& Muleta D (2011). Survey on the usage of plastic bags, their disposal and adverse impacts on environment: A case study in Jimma City, Southwestern Ethiopia. J Toxicol Environ Health Sci 3(8): 234-248.

5. Flores MC (2008). Plastic materials and environmental externalities: Structural causes and corrective policy.

6. Macur BM \& Pudlowski ZJ (2009). Plastic bags-a hazard for the environment and a challenge for contemporary engineering educators. World Trans. Engineer. Technol. Educ 7(2): 122-126.

7. Hasson R, Leiman A, \& Visser M (2007). The Economics of Plastic Bag 
Legislation in South Africa 1. S Afr J Econ 75(1): 66-83.

8. Xing X (2009). Study on the ban on free plastic bags in China. J Sustain Dev 2(1):156-158.

9. Bjerkli CL (2005). The cycle of plastic waste: An analysis on the informal plastic recovery system in Addis Ababa, Ethiopia. (Geografisk institutt).

10. Verghese K, Lewis H, Fitzpatrick L, Hayes G, \& Hedditch B (2009). Environmental impacts of shopping bags. Report for Woolworths Limited, Ref. number: SPA1039WOW-01:1-36.

11. Moroi $\mathrm{T} \&$ Takahashi $\mathrm{T}$ (2002). Erratum ibid. B 539:303.

12. Gap GG (2017) World economic forum. Cologny/Geneva.

13. Magazine \& Sustain (2019). Plastic Pollution, Fall/Winter (39).

14. Bai M, Zhu L, An L, Peng G, \& Li D (2018). Estimation and prediction of plastic waste annual input into the sea from China. Acta Oceanol Sin 37(11):26-39.

15. Geyer R, Jambeck JR, \& Law KL (2017). Production, use, and fate of all plastics ever made. Sci. $A d v$ 3(7):e1700782.

16. Jambeck JR, et al. (2015). Plastic waste inputs from land into the ocean. Sci 347(6223): 768-771.

17. Goebel C, et al. (2014). Energy informatics. Bus. Inform. Syst Eng 6(1): 25-31.

18. Shim WJ \& Thomposon RC (2015). Microplastics in the ocean. Arch Environ Con Toxicol 69(3): 265-268.

19. ten Brink P, Schweitzer J-P, Watkins E, \& Howe M (2016). Plastics Marine Litter and the Circular Economy. A briefing by IEEP for the MAVA Foundation. More Information.

20. Bühler-Vidal JO (2017). The business of polyethylene. (Wiley Online Library).

21. Schnurr RE et al. (2018). Reducing marine pollution from single-use plastics (SUPs): A review. Mar Pollut Bull 137:157-171.

22. Denison R \& Ruston J (1990). Recycling and incineration: evaluating the choices (Island Press).
23. Blackstone Jr JO (1996). Device and method for electronically measuring the fullness of a trash receptacle. (Google Patents).

24. Caruso C, Colorni A, \& Paruccini M (1993). The regional urban solid waste management system: A modelling approach. Eur J Oper Res 70(1): 16-30.

25. Demirbas A (2011). Waste management, waste resource facilities and waste conversion processes. Energ. Convers Manage 52(2):1280-1287.

26. Poortinga W, Sautkina E, Thomas GO, \& Wolstenholme E (2016). The English plastic bag charge: Changes in attitudes and behaviour.

27. Dikgang J \& Visser M (2012). Behavioural response to plastic bag legislation in Botswana. $S$ Afr J Econ 80(1): 123-133.

28. Convery F, McDonnell S, \& Ferreira S (2007). The most popular tax in Europe? Lessons from the Irish plastic bags levy. J Environ Econ Manage 38(1): 111.

29. Wagner TP (2017). Reducing single-use plastic shopping bags in the USA. Waste Manage 70: 3-12.

30. Martinho G, Balaia N, \& Pires A (2017). The Portuguese plastic carrier bag tax: The effects on consumers' behavior. Waste Manage 61: 3-12.

31. Rivers N, Shenstone-Harris S, \& Young $\mathrm{N}$ (2017). Using nudges to reduce waste? The case of Toronto's plastic bag levy. $J$ Environ Manage 188: 153-162.

32. Jakovcevic A, et al. (2014). Charges for plastic bags: Motivational and behavioral effects. J Environ Psychol 40: 372-380.

33. Romer JR \& Foley S (2012). A Wolf in Sheep's Clothing: The Plastics Industry's" Public Interest" Role in Legislation and Litigation of Plastic Bag Laws in California. Gold Gate Univ Environ Law J 5(2): 8.

34. Clapp J \& Swanston L (2009). Doing away with plastic shopping bags: international patterns of norm emergence and policy implementation. Environ Pol 18(3): 315-332. 
35. Nielsen TD, Holmberg K, \& Stripple J (2019). Need a bag? A review of public policies on plastic carrier bags-Where, how and to what effect? Waste Manage 87: 428-440.

36. Xanthos D \& Walker TR (2017). International policies to reduce plastic marine pollution from single-use plastics (plastic bags and microbeads): a review. Mar Pollut Bull 118(1-2): 17-26.

37. Kibria G (2017). Plastic Waste, Plastic Pollution-A Threat to All Nations. (Technical Report 2017. http://dx. doi. org/10.13140/RG. 2.2. 11169.51048).

38. Zaman $\mathrm{T}$ (2010). The prevalence and environmental impact of single use plastic products. Pub. Health Manage \& Policy: An Online Textbook, 11th edition Retrieved November 23: 2011.

39. Laist DW (1987). Overview of the biological effects of lost and discarded plastic debris in the marine environment. Mar Pollut Bull 18(6): 319-326.

40. Anderson A \& Bisong C (2017) Plastic Bags.

41. Atsdr U (1997) Agency for toxic substances and disease registry. Case Studies in J Environ Med http://www. atsdr. cdc. gov/HEC/CSEM/csem. html.

42. Ohyama K, Nagai F, \& Tsuchiya Y (2001) Certain styrene oligomers have proliferative activity on MCF-7 human breast tumor cells and binding affinity for human estrogen receptor. Environ. Health. Perspect 109(7): 699-703.

43. Joyner CC \& Frew S (1991). Plastic pollution in the marine environment. Ocean Dev Int Law 22(1): 33-69.

44. Stachowitsch M (2019) Plastic. The Beachcomber's Guide to Marine Debris, (Springer), pp 87-158.

45. Ryan PG, Moore CJ, van Franeker JA, \& Moloney CL (2009). Monitoring the abundance of plastic debris in the marine environment. Philos Trans $R$ Soc 364(1526): 1999-2012.

46. Tawhid KG (2004). Causes and effects of water logging in Dhaka City, Bangladesh. TRITA-LWR MSc thesis, Departt. of Land and Water Res. Engineer., Royal Instit. of Tech, Stockholm.
47. Bergsten CF (2009). Pacific Asia and the Asia Pacific: The Choices for APEC. (Peterson Institute for International Economics).

48. Ragaert K (2016). Trends in mechanical recycling of thermoplastics. Kunststoff Kolloquium Leoben, pp 159-165.

49. UNEP-WCMC I (2014). The world database on protected areas (WDPA). Cambridge, UK.

50. Jalil MA, Mian MN, \& Rahman MK (2013) Using plastic bags and its damaging impact on environment and agriculture: An alternative proposal. Int J Train Dev 3(4): 1-14.

51. Aiqin Z, Zizhong L, \& Yuanshi G (2005). Effects of biodegradable mulch film on corn growth and its degradation in field. J China Agric Univ.

52. Ramli H, Tuah PM, \& Lamjin S (2016). Screening of Isolated Rhizospheric Bacteria of Pittosporum Resiniferum Hemsl With Toluene.

53. Kabir E, Kaur R, Lee J, Kim K-H, \& Kwon EE (2020). Prospects of biopolymer technology as an alternative option for non-degradable plastics and sustainable management of plastic wastes. J Cleam Prod 120536.

54. Alshehrei F (2017). Biodegradation of synthetic and natural plastic by microorganisms. $J$ Appl Environ Microbiol 5(1): 8-19.

55. Szyszkowska A \& Galas D (2017). Properties, application and degradation of plastics. NAFTA 19: 20.

56. Lambert S \& Wagner M (2017). Environmental performance of biobased and biodegradable plastics: the road ahead. Chem Soc Rev 46(22): 68556871.

57. Saini RD (2017). Biodegradable polymers. Int J Appl Chem 13(2): 179196.

58. Kasirajan S \& Ngouajio M (2012). Polyethylene and biodegradable mulches for agricultural applications: a review. Agron Sustain Dev 32(2): 501-529.

59. Tiwari AK, Gautam M, \& Maurya HK (2018). Recent development of biodegradation techniques of polymer. Int J Res Granthaalayah 6: 414-452. 
60. Elbanna K, Lütke-Eversloh $\mathrm{T}$, Jendrossek D, Luftmann H, \& Steinbüchel A (2004). Studies on the biodegradability of polythioester copolymers and homopolymers by polyhydroxyalkanoate (PHA)-degrading bacteria and PHA depolymerases. Arch Microbiol 182(2-3): 212-225.

61. Kenny ST, et al. (2008). Up-cycling of PET (polyethylene terephthalate) to the biodegradable plastic PHA (polyhydroxyalkanoate). Environ Sci Technol 42(20): 7696-7701.

62. Boyandin AN, et al. (2013). Microbial degradation of polyhydroxyalkanoates in tropical soils. Int Biodeterior Biodegradation 83: 77-84.

63 Ikada Y \& Tsuji H (2000). Biodegradable polyesters for medical and ecological applications. Macromol. Rap. Commun 21(3): 117-132.

64. Anderson JM \& Shive MS (2012). Biodegradation and biocompatibility of PLA and PLGA microspheres. $A d v$ Ddrug Delivery Rev 64: 72-82.

65. Karamanlioglu M, Preziosi R, \& Robson GD (2017). Abiotic and biotic environmental degradation of the bioplastic polymer poly (lactic acid): a review. Polym Degrad Stabil 137: 122130.

66. Mir S, et al. (2017). The effects of nanoclay on thermal, mechanical and rheological properties of LLDPE/chitosan blend. J Polym Eng 37(2): 143-149.

67. Tribedi P \& Sil A (2014). Cell surface hydrophobicity: a key component in the degradation of polyethylene succinate by $\mathrm{P}$ seudomonas sp. AKS 2. J Appl Mmicrobiol 116(2): 295-303.

68. Karakus K (2016). Polycaprolactone (PCL) based polymer composites filled wheat straw flour. Kastamonu Üni Orman Fakültesi Dergisi 16(1).

69. Sanchez JG, Tsuchii A, \& Tokiwa Y (2000). Degradation of polycaprolactone at $50^{\circ} \mathrm{C}$ by a thermotolerant Aspergillus sp. Biotechnol Lett 22(10): 849-853.

70. Jayasekara R, Harding I, Bowater I, Christie GB, \& Lonergan GT (2005). Biodegradation by composting of surface modified starch and PVA blended films. J Polym Environm 11(2): 49-56.

71. Guarás MP, Ludueña LN, \& Alvarez VA (2017). Development of biodegradable products from modified starches. StarchBased Materials in Food Packaging, (Elsevier), pp 77-124.

72. Tokiwa Y, Calabia BP, Ugwu CU, \& Aiba S (2009). Biodegradability of plastics. Int J Mol Sci 10(9): 3722-3742.

73. DeWhitt KC (2012). Systems and methods for recycling plastic. (Google Patents).

74. Zhu Q (2011). An appraisal and analysis of the law of "Plastic-Bag Ban". Energy Procedia 5: 2516-2521.

75. Ritch E, Brennan C, \& MacLeod C (2009). Plastic bag politics: modifying consumer behaviour for sustainable development. Int J Consum 33(2): 168174.

76. Giesler K (2018). The Plastic Problem: Plastic Pollution in Bali. 